\title{
Self-medication with over-the-counter drugs and complementary medications in South Australia's elderly population Lynn Yeen Goh ${ }^{1}$, Agnes I Vitry*1, Susan J Semple ${ }^{1}$, Adrian Esterman ${ }^{2}$ and Mary A Luszcz ${ }^{3}$
}

Address: ${ }^{1}$ Sansom Institute, University of South Australia, Adelaide, South Australia, Australia, ${ }^{2}$ School of Nursing and Midwifery, University of South Australia, Adelaide, South Australia, Australia and ${ }^{3}$ School of Psychology and Flinders Center for Aging Studies, Flinders University, South Australia, Australia

Email: Lynn Yeen Goh - lynnyeen@yahoo.co.uk; Agnes I Vitry* - agnes.vitry@unisa.edu.au; Susan J Semple - susan.semple@unisa.edu.au; Adrian Esterman - adrian.esterman@unisa.edu.au; Mary A Luszcz - mary.luszcz@flinders.edu.au

* Corresponding author

Published: II November 2009

BMC Complementary and Alternative Medicine 2009, 9:42 doi: 10.1 I86/1472-6882-9-42
Received: 30 June 2009

Accepted: II November 2009

This article is available from: http://www.biomedcentral.com/I472-6882/9/42

(C) 2009 Goh et al; licensee BioMed Central Ltd.

This is an Open Access article distributed under the terms of the Creative Commons Attribution License (http://creativecommons.org/licenses/by/2.0), which permits unrestricted use, distribution, and reproduction in any medium, provided the original work is properly cited.

\begin{abstract}
Background: A number of surveys have examined use of complementary and alternative medicines (CAM) in Australia. However, there are limited Australian data on use of CAM and overthe-counter (OTC) medicines in the elderly population. The main aims of this study were to examine self-medication practices with CAM and OTC medicines among older Australians and variables associated with their use.
\end{abstract}

Methods: The Australian Longitudinal Study of Ageing (ALSA) is an ongoing multidisciplinary prospective study of the older population which commenced in 1992 in South Australia. Data collected in 4 waves of ALSA between 1992 and 2004 were used in this study with a baseline sample of 2087 adults aged 65 years and over, living in the community or residential aged care. OTC medicines were classified according to the World Health Organization Anatomical Therapeutic Chemical (ATC) classification. CAM were classified according a modified version of the classification adopted by the Therapeutics Goods Administration (TGA) in Australia.

Results: The prevalence of CAM or OTC use ranged from $17.7 \%$ in $2000-2001$ to $35.5 \%$ in 2003 2004. The top classes of CAM and OTC medicines used remained relatively constant over the study period. The most frequent classes of CAM used were vitamins and minerals, herbal medicines and nutritional supplements while the most commonly used OTC were analgesics, laxatives and low dose aspirin. Females and those of younger age were more likely to be CAM users but no variable was associated with OTC use.

Conclusion: Participants seemed to self-medicate in accordance with approved indications, suggesting they were informed consumers, actively looking after their own health. However, use of analgesics and aspirin are associated with an increased risk of adverse drug events in the elderly. Future work should examine how self-medication contributes to polypharmacy and increases the risk of adverse drug reactions. 


\section{Background}

In Australia, the proportion of adults over the age of 65 in 2005 was $13 \%$ and this figure is expected to more than double by 2051. South Australia has the highest percentage of people aged 65 and over of all Australian states and territories, and this age group is expected to make up $26.5 \%$ of the state's population by $2031[1]$.

Increasing age is associated with increased prevalence of chronic medical conditions [2], a higher number of medicines used, and a higher demand for all medical services, including alternative services $[3,4]$. High levels of selfmedication practices with over-the-counter (OTC) medicines and complementary and alternative medications (CAM) have been reported in Australia and comparable countries [5-9]. The most extensive survey of the South Australian population in 2004 found that CAMs were used by $52.2 \%$ of the respondents with the greatest use in better-educated, higher income, women in the 25-44 years of age group living in a metropolitan area [6]. Use of OTC drugs and CAM in the elderly is of particular interest because several variables associated with old age such as polypharmacy, multiple comorbid illnesses and physiological changes, can increase the risk of adverse drug reactions. Most research on use of CAM and OTC medicines has focused on groups of people with specific chronic conditions. The use of CAM and OTC drugs in the general elderly population remains under-studied internationally.

The Australian Longitudinal Study of Ageing (ALSA) is an ongoing multidisciplinary prospective study of the older population which commenced in 1992 in South Australia. People initially recruited in the study were re-interviewed at multiple time points and ten waves of data collection have been carried out to date. An earlier assessment showed that, at baseline, more than one quarter of the participants were taking at least five medications concurrently [10]. One third of the participants were using non-prescription medications in combination with prescribed medicines. Our study aimed to examine self-medication practices among older Australians, to ascertain the most commonly used non-prescription medications and variables shown in previous research to be associated with their use (i.e. age, gender, education, income and health).

\section{Methods}

ALSA data were used in this study. Methods for inclusion of subjects and survey tools have been described in detail previously [10]. In brief, subjects aged 65 years and over were randomly drawn from the South Australian Electoral Roll. The sample was stratified by age and gender. In this report, 'age' is dichotomized as $65-79$ years or more than 80 years of age. Categories for the other background variables of interest are shown in Table 1. Comprehensive personal interviews were performed in wave 1 (19921993), wave 3 (1994-1995), wave 6 (2000-2001) and wave 7 (2003-2004). Participants were asked about all medicines that they had taken or were supposed to take in the last two weeks. For each medicine, the drug name, dose, duration of treatment, indication for use, whether it was prescribed by a doctor and the reason for use was asked. Reasons for use were grouped a posteriori into categories specific to the type of products. Participants were also asked to show the medicine container to the interviewer.

OTC medicines were classified according to the World Health Organization Anatomical Therapeutic Chemical (ATC classification). Self-reported OTC medicines belonged to ten ATC categories: analgesics, laxatives, antithrombotic agents, antacids, cough and cold preparations, antihistamines, dermatologicals, throat preparations, nasal preparations and antidiarrhoeals. CAM were classified according to the classification adopted by the Therapeutics Goods Administration (TGA) in Australia [11]. The TGA classification was modified to exclude aromatherapy products (no reports) and to include two additional categories, probiotics and combination products to account for those medicines containing multiple ingredients that fell into different classes of CAM. The final CAM classification included seven categories: herbal medicines, traditional medicines (products identified as those used in a specific traditional medical system such as Traditional Chinese Medicine), vitamins and minerals, nutritional supplements, homeopathic medicines, probiotics and combination products.

The most common variables associated with use of CAM or OTC medicines were identified through a literature review of relevant studies published between 1985 and 2007. Relevant variables available in the ALSA dataset included age, gender, education level, income level and self-rated health. Pearson's chi-square tests were carried out to determine the statistical significance of the association between use of CAM and OTC medicines and the variables selected. Data were analysed using the Statistical Package for Social Sciences (SPSS) version 14.0. This study was approved by the Ethics Committee of the University of South Australia.

\section{Results}

\section{Characteristics of participants}

A baseline sample of 2087 participants was interviewed in wave 1 with 1679, 791 and 487 participants re-interviewed in waves 3, 6 and 7 respectively. Attrition was mainly due to mortality (58.7\% at wave 7 ) and refusal to participate (13.6\% at wave 7 ), the latter most often due to frailty and ill-health. 
Table I: Characteristics of participants at waves I, 3, 6 and 7

\begin{tabular}{|c|c|c|c|c|c|c|c|c|}
\hline \multirow[b]{3}{*}{ Variable } & \multicolumn{2}{|c|}{$1992-1993$} & \multicolumn{2}{|c|}{$1994-1995$} & \multicolumn{2}{|c|}{$2000-200 I$} & \multicolumn{2}{|c|}{ 2003-2004 } \\
\hline & Wave I & $N=2087$ & Wave 3 & $N=1679$ & Wave 6 & $N=791$ & Wave 7 & $N=487$ \\
\hline & $\mathbf{N}$ & $\%$ & $\mathbf{N}$ & $\%$ & $\mathbf{N}$ & $\%$ & $\mathbf{N}$ & $\%$ \\
\hline \multicolumn{9}{|l|}{ Age (years) } \\
\hline $65-79$ & 1224 & 58.6 & 893 & 53.2 & 216 & 27.3 & 47 & 9.7 \\
\hline $80+$ & 863 & 41.4 & 786 & 46.8 & 575 & 72.7 & 440 & 90.3 \\
\hline \multicolumn{9}{|l|}{ Gender } \\
\hline Female & 1031 & 49.4 & 854 & 50.9 & 456 & 57.6 & 303 & 62.2 \\
\hline Male & 1056 & 50.6 & 825 & 49.1 & 335 & 42.4 & 184 & 37.8 \\
\hline \multicolumn{9}{|c|}{$\begin{array}{l}\text { Education } \\
\text { (Age when left school) }\end{array}$} \\
\hline$<14$ years & 336 & 16.3 & 262 & 15.4 & 105 & 13.3 & 65 & 13.4 \\
\hline$\geq 14$ years & 1725 & 83.7 & 1399 & 84.6 & 684 & 86.7 & 420 & 86.6 \\
\hline Missing & 26 & & 18 & & 2 & & 2 & \\
\hline \multicolumn{9}{|l|}{ Tertiary education } \\
\hline Yes & 700 & 33.9 & 570 & 34.2 & 278 & 35.2 & 177 & 36.5 \\
\hline No & 1367 & 66.1 & 1096 & 65.8 & 512 & 64.8 & 308 & 63.5 \\
\hline Missing & 20 & & 13 & & I & & 2 & \\
\hline \multicolumn{9}{|l|}{ Income Level } \\
\hline$<\$ 12,000$ & 686 & 35.5 & 559 & 40.9 & 165 & 30.3 & 116 & 35.6 \\
\hline$\$ 12,000-\$ 30,000$ & 1083 & 56.1 & 719 & 52.6 & 312 & 57.4 & 146 & 44.8 \\
\hline$>\$ 30,000$ & 161 & 8.3 & 90 & 6.6 & 67 & 12.3 & 64 & 19.6 \\
\hline Missing & 157 & & 311 & & 247 & & 161 & \\
\hline \multicolumn{9}{|l|}{ Self-rated health } \\
\hline Excellent & 191 & 9.2 & 129 & 8.2 & 64 & 9.8 & 16 & 3.9 \\
\hline Very Good & 599 & 28.8 & 410 & 25.9 & 181 & 27.7 & 85 & 20.5 \\
\hline Good & 633 & 30.4 & 534 & 33.8 & 224 & 34.3 & $17 \mid$ & 41.2 \\
\hline Fair & 477 & 22.9 & 403 & 25.5 & 147 & 22.5 & 113 & 27.2 \\
\hline Poor & 181 & 8.7 & 106 & 6.7 & 37 & 5.7 & 30 & 7.2 \\
\hline Missing & 6 & & 97 & & 138 & & 72 & \\
\hline
\end{tabular}

Missing data are not included in the calculation of the percentages

At baseline there were approximately equal numbers of men and women and $84 \%$ reported leaving school at age fourteen or over. The percentage of female participants increased from $49.4 \%$ in $1992-1993$ to $62.2 \%$ in 2003 2004. The percentage of participants over the age of 80 years increased from $41.4 \%$ in the 12 -year period between $1992-1993$ to $90.3 \%$ in $2003-2004$ [Table 1]. Across the waves, the majority of participants rated their own health as good, very good or excellent and about of third of participants rated their health as fair or poor [Table 1].

\section{Prevalence of self-medication}

The range of participants reporting using either at least one CAM or one OTC medicine varied from $19.4 \%$ in $1992-1993$ to $35.5 \%$ in $2003-2004$ [Table 2]. Correspondingly, when examined separately, the use of CAM and OTC medicines varied from $12.8 \%$ to $17.0 \%$, and $8.6 \%$ to $24.2 \%$ respectively over this time period.

Top classes of CAM and OTC use were relatively constant across the waves [Table 3]. Vitamins and minerals were

Table 2: Number of participants using either CAM and OTC medicines

\begin{tabular}{|c|c|c|c|c|c|c|c|c|}
\hline & \multicolumn{2}{|c|}{ 1992-1993 } & \multicolumn{2}{|c|}{ 1994-1995 } & \multicolumn{2}{|c|}{$2000-2001$} & \multicolumn{2}{|c|}{$2003-2004$} \\
\hline & Wave I & $N=2087$ & Wave 3 & $N=1679$ & Wave 6 & $N=791$ & Wave 7 & $N=487$ \\
\hline Variable & $\mathbf{N}$ & $\%$ & $\mathbf{N}$ & $\%$ & $\mathbf{N}$ & $\%$ & $\mathbf{N}$ & $\%$ \\
\hline CAM or OTCI & 404 & 19.4 & 460 & 27.4 & 140 & 17.7 & 173 & 35.5 \\
\hline OTC only & 268 & 12.8 & 278 & 16.6 & 79 & 10.0 & 83 & 17.0 \\
\hline CAM only & 180 & 8.6 & 241 & 14.4 & 71 & 9.0 & 118 & 24.2 \\
\hline
\end{tabular}

\footnotetext{
I Users of either one CAM or OTC medicine.
} 
Table 3: Prevalence of use of CAM and OTC medicines

\begin{tabular}{|c|c|c|c|c|c|c|c|c|c|}
\hline & & \multicolumn{2}{|c|}{ 1992-1993 } & \multicolumn{2}{|c|}{ 1994-1995 } & \multicolumn{2}{|c|}{$2000-200$ I } & \multicolumn{2}{|c|}{ 2003-2004 } \\
\hline & & Wave I & $N=2087$ & Wave 3 & $N=1679$ & Wave 6 & $\mathbf{N}=791$ & Wave 7 & $N=487$ \\
\hline & Classes of CAM/OTC & $\mathbf{N}$ & $\%$ & $\mathbf{N}$ & $\%$ & $\mathbf{N}$ & $\%$ & $\mathbf{N}$ & $\%$ \\
\hline \multirow[t]{6}{*}{ CAM } & Vitamins \& minerals & 113 & 5.4 & 155 & 9.2 & 53 & 6.7 & 68 & 14.0 \\
\hline & Herbal medicines & 50 & 2.4 & 69 & 4.1 & 23 & 2.9 & 27 & 5.5 \\
\hline & Nutritional supplements & 34 & 1.6 & 54 & 3.2 & 26 & 3.3 & 37 & 7.6 \\
\hline & Homeopathic medicines & 4 & 0.2 & 5 & 0.3 & 0 & 0.0 & I & 0.2 \\
\hline & Probiotics & 3 & 0.1 & 4 & 0.2 & 0 & 0.0 & 0 & 0.0 \\
\hline & Combination products & 43 & 2.1 & 49 & 2.9 & 9 & I.I & 25 & 5.1 \\
\hline \multirow[t]{12}{*}{ OTC } & Analgesics & 112 & 5.4 & 127 & 7.6 & 44 & 5.6 & 43 & 8.8 \\
\hline & Laxatives & 89 & 4.3 & 76 & 4.5 & 16 & 2.0 & 25 & 5.1 \\
\hline & Antithrombotic agents & 34 & 1.6 & 43 & 2.6 & 17 & 2.1 & 10 & 2.1 \\
\hline & Antacids & 19 & 0.9 & 14 & 0.8 & 1 & 0.1 & 6 & 1.2 \\
\hline & Cough \& cold preps & 16 & 0.8 & 18 & 1.1 & 0 & 0.0 & 5 & 1.0 \\
\hline & Antihistamines & 7 & 0.3 & 4 & 0.2 & 2 & 0.3 & 1 & 0.2 \\
\hline & Dermatologicals & 3 & 0.1 & 4 & 0.2 & 1 & 0.1 & 0 & 0.0 \\
\hline & Throat preparations & 4 & 0.2 & 0 & 0.0 & 0 & 0.0 & 0 & 0.0 \\
\hline & Nasal preparations & 2 & 0.1 & 5 & 0.3 & 0 & 0.0 & 0 & 0.0 \\
\hline & Antidiarrhoeals & 2 & 0.1 & 1 & 0.1 & 0 & 0.0 & 0 & 0.0 \\
\hline & Otherl & 11 & 0.5 & 16 & 1.0 & 4 & 0.5 & 4 & 0.8 \\
\hline & Unknown² & II & 0.5 & 10 & 0.6 & 3 & 0.4 & 12 & 2.5 \\
\hline
\end{tabular}

The percentages show the proportions of participants reporting to use at least one of the classes of CAM or OTC medicines

I Other CAM and OTC classes that were less commonly reported

2 Non-prescription medicines of unknown ingredients that could not be classified

the most commonly used CAM products at all waves (5.4\% to $14.0 \%)$. This was followed by herbal medicines $(2.4 \%$ to $5.5 \%)$ and nutritional supplements $(1.6 \%$ to $7.6 \%)$. Most of the combination products $(2.1 \%$ to $5.1 \%)$ included different herbal combinations. Multivitamins and vitamin $\mathrm{C}$ were the most commonly used vitamins. Garlic, celery and gingko biloba were the most commonly used herbal medicines and cod liver oil was the most popular nutritional supplement [Table 4].

Analgesics were the most common class of OTC drugs at all waves ( 5.4 to $8.8 \%$ ), followed by laxatives $(2.0 \%$ to $5.1 \%$ ) and antithrombotic agents (low dose aspirin) (1.6\% to $2.6 \%)$. The most commonly used analgesic was

Table 4: Most commonly used CAM

\begin{tabular}{|c|c|c|c|c|c|c|c|c|}
\hline & \multicolumn{2}{|c|}{ 1992-1993 } & \multicolumn{2}{|c|}{ |994-| 995} & \multicolumn{2}{|c|}{ 2000-200I } & \multicolumn{2}{|c|}{ 2003-2004 } \\
\hline & Wave I & $N=180$ & Wave 3 & $\mathbf{N}=\mathbf{2 4 I}$ & Wave 6 & $\mathbf{N}=7 \mathbf{I}$ & Wave 7 & $\mathbf{N}=118$ \\
\hline CAM & $\mathbf{N}$ & $\%$ & $\mathbf{N}$ & $\%$ & $\mathbf{N}$ & $\%$ & $\mathbf{N}$ & $\%$ \\
\hline \multicolumn{9}{|c|}{ Vitamins and minerals } \\
\hline Multivitamins & 40 & 22.2 & 57 & 23.7 & 22 & 31 & 33 & 28 \\
\hline Vitamin C & 32 & 17.8 & 47 & 19.5 & 8 & 11.3 & 23 & 20.3 \\
\hline Vitamin B & 19 & 10.6 & 31 & 12.9 & 8 & 11.3 & 5 & 4.2 \\
\hline Vitamin E & 18 & 10 & 43 & 17.8 & 16 & 22.5 & 9 & 7.6 \\
\hline \multicolumn{9}{|c|}{ Herbal medications } \\
\hline Garlic & 24 & 13.3 & 22 & 9.1 & 3 & 4.2 & 2 & 1.7 \\
\hline Celery & 13 & 7.2 & 18 & 7.5 & 3 & 4.2 & 1 & 0.8 \\
\hline Gingko biloba & 2 & I.I & 5 & 2.1 & 10 & 14.1 & 9 & 7.6 \\
\hline \multicolumn{9}{|c|}{ Nutritional supplements } \\
\hline Cod liver oil & 22 & 12.2 & 37 & 15.4 & 9 & 12.7 & II & 9.3 \\
\hline Fish oil & 6 & 3.3 & 5 & 2.1 & 3 & 4.2 & 8 & 6.8 \\
\hline Glucosamine & 0 & 0 & 0 & 0 & 4 & 5.6 & 10 & 8.5 \\
\hline
\end{tabular}

The percentages are calculated over the number of participants that reported use of at least one CAM indicated as $\mathrm{N}$ 
paracetamol, while laxatives were mostly senna, docusate or a mixture of both.

\section{Variables affecting self-medication}

OTC use was not associated with age, gender, education level and tertiary education in any of the four waves [Table $5]$. Although there was a statistically significant association between income and OTC use in waves 3 and 6 , the pattern of results was inconsistent for the different waves. The same was true for self-rated health.

CAM use was associated with age and gender [Table 6]. The younger elderly people were more likely to use CAM than the older group ( 80 years and over) in all four waves. The difference in use remained constant over time, with those age 65 to 79 years old being 1.5 to 1.6 times more likely to use CAM than those aged 80 years or more. Females were also found to be more likely users of CAM in waves 1, 3 and 6 (the results were not statistically significant in wave 7). CAM use was not associated with education level, tertiary education, income level and self- rated health in any wave except in wave 7 where use of CAM was higher in participants with tertiary education.

\section{Reasons for using CAM and OTC medicines}

The main reasons for using analgesics were headache and pain (Table 7). Low dose aspirin was reported to be used for blood thinning and/or stroke prevention by most participants (Table 8). However, some respondents reported unlikely reasons for use such as for lowering cholesterol levels, hypertension and for sleep.

The most common reasons for use of multivitamins were supplementation and maintenance of general health (Table 9). Vitamin C was predominantly used to ward off colds, to boost the immune system and for general health maintenance across all four waves (Table 10).

\section{Discussion}

Up to a third of older participants in the current study used either CAM or OTC medicines. The study differed from Australian studies conducted earlier in several ways

Table 5: Prevalence of OTC use across variables of interest

\begin{tabular}{|c|c|c|c|c|c|c|c|c|}
\hline \multirow[b]{3}{*}{ Variable } & \multicolumn{2}{|c|}{$1992-1993$} & \multicolumn{2}{|c|}{ |994-|995 } & \multicolumn{2}{|c|}{$2000-2001$} & \multicolumn{2}{|c|}{ 2003-2004 } \\
\hline & Wave I & $N=268$ & Wave 3 & $N=278$ & Wave 6 & $\mathbf{N}=79$ & Wave 7 & $\mathbf{N}=\mathbf{8 3}$ \\
\hline & $\mathbf{N}$ & $\%$ & $\mathbf{N}$ & $\%$ & $\mathbf{N}$ & $\%$ & $\mathbf{N}$ & $\%$ \\
\hline \multicolumn{9}{|l|}{ Age (years) } \\
\hline $65-79$ & 159 & 13.0 & 148 & 16.6 & 27 & 12.5 & 8 & 17.0 \\
\hline $80+$ & 109 & 12.6 & 130 & 16.5 & 52 & 9.0 & 75 & 17.0 \\
\hline$P$ value & \multicolumn{2}{|c|}{0.809} & \multicolumn{2}{|c|}{0.985} & \multicolumn{2}{|c|}{0.149} & \multicolumn{2}{|c|}{0.997} \\
\hline \multicolumn{9}{|l|}{ Gender } \\
\hline Female & 146 & 14.2 & 149 & 17.4 & 52 & 11.4 & 51 & 16.8 \\
\hline Male & 122 & 11.6 & 129 & 15.6 & 27 & 8.1 & 32 & $17.4 \%$ \\
\hline$P$ value & \multicolumn{2}{|c|}{0.075} & \multicolumn{2}{|c|}{0.318} & \multicolumn{2}{|c|}{0.121} & \multicolumn{2}{|c|}{0.873} \\
\hline \multicolumn{9}{|c|}{$\begin{array}{l}\text { Education } \\
\text { (Age when left school) }\end{array}$} \\
\hline$<14$ years & 47 & 14.0 & 47 & 17.9 & 14 & 13.3 & II & 16.9 \\
\hline$\geq 14$ years & 220 & 12.8 & 227 & 16.2 & 65 & 9.5 & 72 & 17.1 \\
\hline$P$ value & \multicolumn{2}{|c|}{0.538} & \multicolumn{2}{|c|}{0.493} & \multicolumn{2}{|c|}{0.223} & \multicolumn{2}{|c|}{0.965} \\
\hline \multicolumn{9}{|l|}{ Tertiary education } \\
\hline Yes & 98 & 14.0 & 101 & 17.7 & 27 & 9.7 & 31 & 17.5 \\
\hline No & 170 & 12.4 & 176 & 16.1 & 52 & 10.2 & 52 & 16.9 \\
\hline$P$ value & \multicolumn{2}{|c|}{0.316} & \multicolumn{2}{|c|}{0.388} & \multicolumn{2}{|c|}{0.843} & \multicolumn{2}{|c|}{0.859} \\
\hline \multicolumn{9}{|l|}{ Income Level } \\
\hline$<\$ 12,000$ & 89 & 13.0 & 97 & 17.4 & 26 & 15.8 & 23 & 19.8 \\
\hline$\$ 12,000-\$ 30,000$ & 137 & 12.7 & 111 & 15.4 & 26 & 8.3 & 24 & 16.4 \\
\hline$>\$ 30,000$ & 25 & 15.5 & 27 & 30.0 & 5 & 7.5 & 8 & 12.5 \\
\hline$P$ value & \multicolumn{2}{|c|}{0.598} & \multicolumn{2}{|c|}{0.003} & \multicolumn{2}{|c|}{0.029} & 0.4 & \\
\hline Perceived Health & & & & & & & & \\
\hline Excellent & 19 & 9.9 & 17 & 13.2 & 4 & 6.3 & 4 & 25.0 \\
\hline Very Good & 63 & 10.5 & 58 & 14.1 & 25 & 13.8 & 13 & 15.3 \\
\hline Good & 96 & 15.2 & 105 & 19.7 & 21 & 9.4 & 25 & 14.6 \\
\hline Fair & 73 & 15.3 & 73 & 18.1 & 18 & 12.2 & 24 & 21.2 \\
\hline Poor & 17 & 9.4 & 14 & 13.2 & 4 & 10.8 & 6 & 20.2 \\
\hline$P$ value & 0.0 & & 0.0 & & 0.4 & & 0.5 & \\
\hline
\end{tabular}

The percentages are calculated over the total number of participants in each category of the variable of interest 
Table 6: Prevalence of CAM use across variables of interest

\begin{tabular}{|c|c|c|c|c|c|c|c|c|}
\hline \multirow[b]{3}{*}{ Variable } & \multicolumn{2}{|c|}{$1992-1993$} & \multicolumn{2}{|c|}{ 1994-1995 } & \multicolumn{2}{|c|}{$2000-2001$} & \multicolumn{2}{|c|}{ 2003-2004 } \\
\hline & \multirow{2}{*}{$\frac{\text { Wave I }}{\mathbf{N}}$} & $N=180$ & \multirow{2}{*}{$\frac{\text { Wave } 3}{\mathbf{N}}$} & $N=24 I$ & \multirow{2}{*}{$\frac{\text { Wave } 6}{\mathbf{N}}$} & \multirow{2}{*}{$\begin{array}{c}\mathbf{N}=\mathbf{7} \mathbf{I} \\
\%\end{array}$} & \multirow{2}{*}{$\begin{array}{c}\text { Wave } 7 \\
\mathbf{N}\end{array}$} & $N=173$ \\
\hline & & $\%$ & & $\%$ & & & & $\%$ \\
\hline \multicolumn{9}{|l|}{ Age (years) } \\
\hline $65-79$ & 122 & 10.0 & 152 & 17.0 & 27 & 12.5 & 17 & 36.2 \\
\hline $80+$ & 58 & 6.7 & 89 & 11.3 & 44 & 7.7 & 101 & 23.0 \\
\hline$P$ value & \multicolumn{2}{|c|}{0.009} & \multicolumn{2}{|c|}{0.001} & \multicolumn{2}{|c|}{0.034} & \multicolumn{2}{|c|}{0.044} \\
\hline \multicolumn{9}{|l|}{ Gender } \\
\hline Female & 102 & 9.9 & 142 & 16.6 & 53 & 11.6 & 81 & 26.7 \\
\hline Male & 78 & 7.4 & 99 & 12.0 & 18 & 5.4 & 37 & 20.1 \\
\hline$P$ value & \multicolumn{2}{|c|}{0.041} & \multicolumn{2}{|c|}{0.007} & \multicolumn{2}{|c|}{0.002} & \multicolumn{2}{|c|}{0.098} \\
\hline \multicolumn{9}{|c|}{$\begin{array}{l}\text { Education } \\
\text { (Age when left school) }\end{array}$} \\
\hline$<14$ years & 30 & 8.9 & 39 & 14.9 & 10 & 9.5 & 16 & 24.6 \\
\hline$\geq 14$ years & 149 & 8.6 & 200 & 14.3 & 61 & 8.9 & 102 & 24.3 \\
\hline P value & \multicolumn{2}{|c|}{0.862} & \multicolumn{2}{|c|}{0.803} & \multicolumn{2}{|c|}{0.840} & \multicolumn{2}{|c|}{0.954} \\
\hline \multicolumn{9}{|l|}{ Tertiary education } \\
\hline Yes & 63 & 9.0 & 92 & 16.1 & 27 & 9.7 & 56 & 31.6 \\
\hline No & 116 & 8.5 & 149 & 13.6 & 44 & 8.6 & 62 & 20.1 \\
\hline $\mathrm{P}$ value & 0.6 & & 0.1 & & 0.6 & & 0.0 & \\
\hline Income Level & & & & & & & & \\
\hline$<\$ 12,000$ & 52 & 7.6 & 82 & 14.7 & 18 & 10.9 & 33 & 28.4 \\
\hline$\$ 12,000-\$ 30,000$ & 101 & 9.3 & 120 & 16.7 & 29 & 9.3 & 34 & 23.3 \\
\hline$>\$ 30,000$ & 12 & 7.5 & 13 & 14.4 & 10 & 14.9 & 12 & 18.8 \\
\hline$P$ value & 0.3 & & 0.5 & & 0.3 & & 0.3 & \\
\hline Self-rated health & & & & & & & & \\
\hline Excellent & 16 & 8.4 & 17 & 13.2 & 12 & 18.8 & 7 & 43.8 \\
\hline Very Good & 58 & 9.7 & 64 & 15.6 & 17 & 9.4 & 24 & 28.2 \\
\hline Good & 56 & 8.8 & 90 & 16.9 & 23 & 10.3 & 43 & 25.1 \\
\hline Fair & 38 & 8.0 & 53 & 13.2 & II & 7.5 & 23 & 20.4 \\
\hline Poor & 12 & 6.6 & II & 10.4 & 5 & 13.5 & 6 & 20.0 \\
\hline$P$ value & 0.7 & & 0.3 & & 0.1 & & 0.2 & \\
\hline
\end{tabular}

The percentages are calculated over the total number of participants in each category of the variable of interest

Table 7: Reasons for use of analgesics

\begin{tabular}{|c|c|c|c|c|c|c|c|c|}
\hline \multirow[b]{3}{*}{ Reasons of use of analgesics } & \multicolumn{2}{|c|}{ |992-| 993} & \multicolumn{2}{|c|}{ 1994-1995 } & \multicolumn{2}{|c|}{$2000-200 I$} & \multicolumn{2}{|c|}{ 2003-2004 } \\
\hline & Wave I & $N=112$ & Wave 3 & $N=127$ & Wave 6 & $N=44$ & Wave 7 & $N=43$ \\
\hline & $\mathbf{N}$ & $\%$ & $\mathbf{N}$ & $\%$ & $\mathbf{N}$ & $\%$ & $\mathbf{N}$ & $\%$ \\
\hline Headache & 35 & 31.8 & 41 & 32.3 & 5 & 11.4 & 6 & 14 \\
\hline Specific pain & 19 & 17.3 & 16 & 12.6 & 4 & 9.1 & 5 & 11.6 \\
\hline General pain & 18 & 16.4 & 26 & 20.5 & 25 & 56.8 & 22 & 51.2 \\
\hline Other & 21 & 19.1 & 25 & 19.7 & 5 & 11.4 & 3 & 7.0 \\
\hline Arthritic pain & 11 & 10.0 & 15 & 11.8 & 2 & 4.5 & 4 & 9.3 \\
\hline Multiple reasons & 6 & 5.5 & 4 & 3.1 & 3 & 6.8 & 3 & 7.0 \\
\hline Missing & 2 & & 0 & & 0 & & 0 & \\
\hline
\end{tabular}

The percentages are calculated over the number of participants that reported use of analgesics 
Table 8: Reasons for use of antithrombotic agents

\begin{tabular}{|c|c|c|c|c|c|c|c|c|}
\hline & \multicolumn{2}{|c|}{$1992-1993$} & \multicolumn{2}{|c|}{ 1994-1995 } & \multicolumn{2}{|c|}{$2000-2001$} & \multicolumn{2}{|c|}{ 2003-2004 } \\
\hline & Wave I & $\mathbf{N}=\mathbf{3 4}$ & Wave 3 & $N=43$ & Wave 6 & $N=17$ & Wave 7 & $\mathbf{N}=10$ \\
\hline Reasons of use of antithrombotic agents & $\mathbf{N}$ & $\%$ & $\mathbf{N}$ & $\%$ & $\mathbf{N}$ & $\%$ & $\mathbf{N}$ & $\%$ \\
\hline Blood thinning \&/or stroke prevention & 27 & 87.0 & 36 & 85.7 & 16 & 94.1 & 6 & 60.0 \\
\hline Unlikely reasons & 4 & 12.9 & 5 & 11.6 & I & 5.9 & 4 & 40.0 \\
\hline Other & 0 & 0.0 & I & 2.3 & 0 & 0.0 & 0 & 0.0 \\
\hline Missing & 3 & & I & & 0 & & 0 & \\
\hline
\end{tabular}

The percentages are calculated over the number of participants that reported use of antithrombotic agents

$[6,12-14]$. Firstly, this study focused on a targeted population, namely elderly people aged 65 and older in South Australia. The study also sought to provide a broader insight into the self-medication practices of the elderly in examining use of both CAM and OTC medicines and reasons for use.

Fewer elderly people in our survey reported use of OTC medicines ( $10 \%$ to $17 \%$ ) compared to a range of $31 \%$ to $97 \%$ in other surveys [15-19]. However, these surveys were carried out in the United States (US). The discrepancies observed may be explained by differences in the definition of OTC medicines and differences in subsidised accessibility to prescription medicines between Australia and the US. Non-prescription vitamins and minerals are considered as OTC medicines by the US Food and Drug Administration (FDA) and CAM by the TGA $[11,20]$. Furthermore, there is no national subsidisation scheme for pharmaceuticals in the US while in Australia, residents may prefer to get most medicines on prescription due to low co-payment fees. This is particularly relevant for medicines such as paracetamol which is widely used in both countries and which is available as a subsidised prescription medicine only in Australia.

The reported use of CAM (8.6\% to $24.2 \%$ ) in our study was lower than in previous Australian studies $37 \%$ to $58 \%$ ) $[6,14,21-23]$. Several differences in the methods used may account for this variation. All but two of the previous studies included alternative services such as acu- puncture, massage and chiropractic in their definition of CAM. The time interval over which participants reported has also varied. A 2004 survey in South Australia found $37 \%$ of people older than 65 years were CAM users but participants were asked whether they had used any CAM over the past year [6]. A study with a similar definition of use to this current study in terms of time interval and products surveyed reported $43 \%$ of CAM use [21]. However, the format of the interview where examples of each type of supplement were provided may have prompted more reports of CAM use [21]. A recent study in Iceland was conducted using similar methods to ALSA where simultaneous recording of herbal and dietary supplements (HADS) and prescription medicine use was carried out [24]. This study reported a prevalence of $80 \%$ of HADS use among their participants.

The top three classes of OTC drugs used by our respondents did not change between 1992 and 2004 and were similar to those described previously in the 1989-1990 Australian National Health Survey [25]. Analgesics were the most commonly used class of OTC medicines, predominantly paracetamol. Painful chronic conditions are prevalent in the elderly and therefore, many are amenable to treatment by OTC analgesics. Other international studies have also found analgesics to be the most commonly reported OTC class, though aspirin and non-steroidal anti-inflammatory drugs (NSAIDs) were more commonly used than paracetamol $[7,15,18,19]$. It is unclear whether in these studies all aspirin use was grouped under analge-

Table 9: Reasons for use of multivitamins

\begin{tabular}{|c|c|c|c|c|c|c|c|c|}
\hline \multirow[b]{3}{*}{ Reasons of use of multivitamins } & \multicolumn{2}{|c|}{$1992-1993$} & \multicolumn{2}{|c|}{$1994-1995$} & \multicolumn{2}{|c|}{$2000-200 I$} & \multicolumn{2}{|c|}{ 2003-2004 } \\
\hline & Wave I & $N=40$ & Wave 3 & $\mathbf{N}=\mathbf{5 7}$ & Wave 6 & $N=22 N=22$ & Wave 7 & $\mathbf{N}=\mathbf{3 3}$ \\
\hline & $\mathbf{N}$ & $\% 1$ & $\mathbf{N}$ & $\% 1$ & $\mathbf{N}$ & $\% 1$ & $\mathbf{N}$ & $\% 1$ \\
\hline Supplement & 19 & 47.5 & 22 & 38.6 & I & 4.5 & 8 & 24.2 \\
\hline General health & 14 & 35.0 & 27 & 47.4 & 21 & 95.5 & 19 & 57.6 \\
\hline Energy boost or tiredness & 4 & 10.0 & 3 & 5.3 & 0 & 0.0 & 1 & 3.0 \\
\hline Other' & 3 & 7.5 & 5 & 8.8 & 0 & 0.0 & 5 & I5. \\
\hline
\end{tabular}

The percentages are calculated over the number of participants that reported use of multivitamins

I Other reasons included nerves or stress, arthritis, cold prevention and immune stimulation and multiple reasons 
Table 10: Reasons for use of vitamin C

\begin{tabular}{|c|c|c|c|c|c|c|c|c|}
\hline \multirow[b]{3}{*}{ Reasons of use of Vitamin C } & \multicolumn{2}{|c|}{ | $992-1993$} & \multicolumn{2}{|c|}{ | $994-1995$} & \multicolumn{2}{|c|}{$2000-2001$} & \multicolumn{2}{|c|}{ 2003-2004 } \\
\hline & Wave I & $\mathbf{N}=32$ & Wave 3 & $\mathbf{N}=\mathbf{4 7}$ & Wave 6 & $\mathbf{N}=\mathbf{8}$ & Wave 7 & $\mathbf{N}=\mathbf{2 3}$ \\
\hline & $\mathbf{N}$ & $\%$ & $\mathbf{N}$ & $\%$ & $\mathbf{N}$ & $\%$ & $\mathbf{N}$ & $\%$ \\
\hline Cold prevention and immune stimulation & 13 & 43.3 & 14 & 30.4 & 0 & 0.0 & 8 & 34.8 \\
\hline General health & 7 & 23.3 & 18 & 39.1 & 8 & 100 & 8 & 34.8 \\
\hline Supplement & 6 & 20.0 & 7 & 15.2 & 0 & 0.0 & 3 & 13.0 \\
\hline Other 1 & 4 & 13.3 & 7 & 15.2 & 0 & 0.0 & 4 & 17.4 \\
\hline Missing & 2 & & I & & 0 & & 0 & \\
\hline
\end{tabular}

The percentages are calculated over the number of participants that reported use of Vitamin C

I Other reasons included muscles or bones, energy boost or tiredness, blood or circulation, arthritis, cardiac or heart health and multiple reasons

sics but in our study, we distinguished between aspirin used at low dose as an antiplatelet agent or at a higher dose as an analgesic agent based on the medicine strength and indication of use. Low dose aspirin was found to be the third most commonly reported class of OTC drugs in our study.

Vitamins and minerals, herbal medicines and nutritional supplements were the three most common classes of CAM reported across all waves. This is consistent with findings reported in other Australian studies [9,21,22]. Multivitamins accounted for about one-third of all CAM used across the waves, followed by Vitamins $\mathrm{C}, \mathrm{B}$ and $\mathrm{E}$ in agreement with the results of previous studies [21-26]. The most common herbal product to be reported in this study was garlic, also in agreement with other studies $[21,26]$, with gingko biloba, marketed for age-related memory impairment, gaining popularity in the latest waves. Cod liver oil was the most popular nutritional supplement across all waves, with glucosamine use emerging as a treatment for arthritis after 2001, consistent with Brownie's prediction in 2000 [21]. One reason for the more recent emergence of this product in the study may be the shift towards inclusion of this product as part of conventional care.

None of the demographic variables tested, age, gender, education, tertiary education, income level and self-rated health was found to be associated with OTC use. The relationship of age and OTC use is equivocal in the literature $[7,16,27,28]$. Greater OTC use was observed in females in the US studies that included multivitamin use $[7,16,27,28]$. Greater educational attainment and poorer self-rated health have been associated with higher use of OTC in some studies $[15,16,27]$.

Female gender and a younger age were the only variables found to be associated with CAM use in our study, in agreement with previous studies [12,14,15,21,23,26,29]. Possible explanations for CAM use were not available in the data because ALSA participants were not asked about attitudinal or psychological factors involved in their choice of medicines. A literature review of variables reported to influence the use of complementary medicines by consumers suggested that the emergence of postmodern values provided the best explanation of consumers' interest in CAM[9]. Postmodern values involved "a new set of beliefs about nature, science, holistic medicine, rejection of authority, individual responsibility and consumerism" [9]. A recent survey of attitudes of Australian consumers to complementary medicines found that many consumers saw their CAM use as "natural" and part of a holistic view of health [30].

Reasons reported for using OTC medicines were consistent with the indications approved by the Australian medicines agency with the exception of low-dose aspirin for which between $5.9 \%$ and $40.0 \%$ of participants reported unlikely reasons. The most common reasons for use of multivitamins were supplementation and maintenance of general health. In a 2004 Australian study that examined beliefs in CAM users, most respondents had no specific medical reason for using CAM but believed they would help their general health. Promotion of general health and prevention of illness were also found the main variables driving the use of CAM in other international studies [9]. Some CAM could also be used for the treatment of symptoms such as glucosamine for arthritis.

There were some potential limitations to our study. Although there was an apparent overall increase of participants reported use of at least one CAM or OTC from $19.4 \%$ at baseline to $35.5 \%$ by 2004 , we did not attempt to assess statistically the time trend given the large amount of missing data due to the high attrition level at wave 7 . Furthermore, slight variations in medication data collection methods in waves 3 and 7, and a higher proportion of women in wave 7 could partly explain the higher use of CAM and OTC medicines observed at this wave. Although many of the ALSA participants were from non-English speaking backgrounds, fluent English was essential and thus, the findings may not be a true reflection of the use 
of CAM or OTC in non-English speaking elderly community in a multi-cultural country. Finally, but like most other studies, the data we gathered was self-reported. However, unlike other studies, respondents were asked to show the medicine containers, even so some medicines could have been overlooked. The reasons for use of CAM were categorized from self-reported reasons by consumers and the categories were set up to reflect as closely as possible the words used by the consumers themselves. Then, it is not possible to infer from this data whether use of CAM for "general health" or as "supplement" reflect different beliefs as regards the therapeutic effect of CAM. The question of whether consumers perceived themselves to be "deficient" in a vitamin or believe that supra-therapeutic doses would improve physical or mental performance cannot be determined from the data collected in the ALSA database.

This study focused on examining the types of non-prescription medications used by older Australians and the association between use and various demographic and health-related factors. Further work is needed to examine how self-medication amongst older people contributes to polypharmacy and increases the risk of adverse drug reactions. Use of NSAIDs and aspirin, for example, are associated with an increased risk of adverse drug events, hospitalization and death, with the elderly being particularly vulnerable [31]. Some OTC medicines may also have severe interactions with prescribed medicines [32].

\section{Conclusion}

Self-medication among the ALSA respondents ranged from $18 \%$ to $36 \%$ between 1992 and 2004. The most frequent classes of CAM were vitamins and minerals, herbal medicines and nutritional supplements, with younger individuals and women more likely to use them. For OTC medicines, the most commonly used were analgesics, laxatives and low dose aspirin. Use of OTC medicines seemed to be done in accord with indications officially approved by the Australian medicine agency. Future work should examine risks associated with the concomitant use of CAM, prescription and OTC medicines.

\section{List of abbreviations}

ABS: Australian Bureau of Statistics; AIHW: Australian Institute of Health and Welfare; LSA: Australian Longitudinal Study of Ageing; ASMI: Australian Self-Medication Industry; ATC: Anatomical Therapeutic Chemical; CAM: Complementary and Alternative Medicines; FDA: US Food and Drug Administration; HADS: Herbal and Dietary Supplements; HIC: Health Insurance Commission; NPS: National Prescribing Service; NSAIDs: Non-Steroidal Anti-Inflammatory Drugs; OTC: Over-The-Counter; TGA: Therapeutic Goods Administration.

\section{Competing interests}

The authors declare that they have no competing interests.

\section{Authors' contributions}

LYG wrote the research proposal, did the review of the literature, performed the analysis and wrote the first draft of the manuscript. AV and SS designed the study, participated in the analysis and the interpretation of the data and reviewed the manuscript. ML conducted the ALSA study, provided raw data and reviewed the manuscript. All authors read and approved the final manuscript.

\section{Acknowledgements}

This study was supported by funding from a National Health and Medical Research Council/Australian Research Council Ageing Well Ageing Productively (AWAP) Program grant (APP ID 401832). We acknowledge the contribution of all the Chief Investigators who assisted with the preparation of this study: Prof. Andrew Gilbert, Associate Prof. Libby Roughead, Prof. Robyn McDermott, Prof. Phil Ryan and Dr. Sepehr Shakib. We thank the ALSA participants, the late Prof Gary Andrews and other staff from the Flinders (University) Centre for Ageing Studies for conducting the study and providing raw data and advice. Grants from the US National Institute of Aging (No. AG08523-02) and the National Health and Medical Research Council (No. 229933) funded the waves included in this report.

\section{References}

I. Australian Bureau of Statistics: Australian Demographic Statistics: June 2007. Canberra: Australian Bureau of Statistics; 2007.

2. Britt HC, Harrison CM, Miller GC, Knox SA: Prevalence and patterns of multimorbidity in Australia. Med J Aust 2008, 189(2):72-77.

3. Willison KD, Andrews GJ: Complementary medicine and older people: past research and future directions. Complement Ther Nurs Midwifery 2004, I 0(2):80-91.

4. Foster DF, Phillips RS, Hamel MB, Eisenberg DM: Alternative medicine use in older Americans. J Am Geriatr Soc 2000, 48(I 2): $1560-1565$.

5. Eisenberg DM, Davis RB, Ettner SL, Appel S, Wilkey S, Van Rompay $M$, Kessler RC: Trends in alternative medicine use in the United States, 1990-1 997: results of a follow-up national survey. JAMA 1998, 280(18): I569-I575.

6. MacLennan AH, Myers SP, Taylor AW: The continuing use of complementary and alternative medicine in South Australia: costs and beliefs in 2004. Med J Aust 2006, I 84(I):27-3I.

7. Hanlon JT, Fillenbaum GG, Ruby CM, Gray S, Bohannon A: Epidemiology of over-the-counter drug use in community dwelling elderly: United States perspective. Drugs Aging 2001, 18(2): |23-|3|.

8. Bradley $C$, Blenkinsopp $A$ : Over the counter drugs. The future for self medication. BM] 1996, 3 I 2(7034):835-837.

9. Easton K: Complementary medicines: attitudes and information needs of consumers and healthcare professionals. Sydney: National Prescribing Service Ltd; 2007.

10. Luszcz M, Giles L, Eckermann S, Edwards P, Browne-Yung K, Hayles C, Trezise K, Andrews M: The Australian Longitudinal Study of Ageing: 15 years of ageing in South Australia. Adelaide: South Australian Department of Families and Communities; 2007.

11. The regulation of complementary medicines in Australia an overview [http://www.tga.gov.au/cm/cmreg-aust.htm]

12. MacLennan $\mathrm{AH}$, Wilson DH, Taylor AW: The escalating cost and prevalence of alternative medicine. Prev Med 2002, 35(2): 166-173.

13. MacLennan AH, Wilson DH, Taylor AW: Prevalence and cost of alternative medicine in Australia. Lancet 1996, 347(900I):569-573.

14. Zhang AL, Xue CC, Lin V, Story DF: Complementary and alternative medicine use by older Australians. Ann N Y Acad Sci 2007, II I 4(I):204-2I5. 
15. Amoako EP, Richardson-Campbell L, Kennedy-Malone L: Self-medication with over-the-counter drugs among elderly adults. J Gerontol Nurs 2003, 29(8): 10-15.

16. Fillenbaum GG, Hanlon JT, Corder EH, Ziqubu-Page T, Wall WE Jr, Brock D: Prescription and nonprescription drug use among black and white community-residing elderly. AmJ Public Health 1993, 83(I I): I577-I582.

17. Hanlon JT, Fillenbaum GG, Burchett B, Wall WE Jr, Service C, Blazer DG, George LK: Drug-use patterns among black and nonblack community-dwelling elderly. Ann Pharmacother 1992, 26(5):679-685.

18. Lam A, Bradley G: Use of self-prescribed nonprescription medications and dietary supplements among assisted living facility residents. J Am Pharm Assoc 2006, 46(5):574-58I.

19. Stoehr GP, Ganguli M, Seaberg EC, Echement DA, Belle S: Over-thecounter medication use in an older rural community: the MoVIES Project. J Am Geriatr Soc 1997, 45(2): I58-165.

20. Rheinstein $\mathrm{PH}$ : Prescription to over-the-counter drug switches. Am Fam Physician 1997, 56(4):121I-1214.

21. Brownie S: Predictors of dietary and health supplement use in older Australians. Aust J Adv Nurs 2006, 23(3):26-32.

22. Lentile CS, Sorensen L, Lemanski L, Roberts MS: Complementary medicines use by Australian veterans. J Pharm Pract Res 2005, 35(2): II0-III.

23. Xue CC, Zhang AL, Lin V, Da Costa C, Story DF: Complementary and alternative medicine use in Australia: a national population-based survey. J Altern Complement Med 2007, I3(6):643-650.

24. Halldorsdottir $\vee$, Almarsdottir $A B$, Gudmundsson $A$, Nikulasdottir $H$, Harris TB, Launer L, Eirksdottir G, Gudnason V: Pattern and Prevalence of herbal and dietary supplements in an elderly cohort: AGES-Reykjavik Study. Copenhagen: John Wiley \& Sons Ltd; 2008.

25. Australian Bureau of Statistics: 1989-1990 National Health Survey: summary of results. Canberra: Australian Bureau of Statistics; 1991.

26. Ness J, Cirillo DJ, Weir DR, Nisly NL, Wallace RB: Use of complementary medicine in older Americans: results from the Health and Retirement Study. Gerontologist 2005, 45(4):516-524.

27. Stoller EP: Prescribed and over-the-counter medicine use by the ambulatory elderly. Med Care I988, 26(1 2): I I49-I I 57.

28. Sharpe TR, Smith MC, Barbre AR: Medicine use among the rural elderly. J Health Soc Behav 1985, 26(2): I I3-I 27.

29. Astin JA, Pelletier KR, Marie A, Haskell WL: Complementary and alternative medicine use among elderly persons: one-year analysis of a Blue Shield Medicare supplement. J Gerontol A Biol Sci Med Sci 2000, 55(I):M4-9.

30. Williamson M, Tudball J, Toms M, Garden F, A G: Information use and needs of complementary medicines users. Sydney: National Prescribing Service Ltd; 2008.

31. Visser LE, Graatsma HH, Stricker BH: Contraindicated NSAIDs are frequently prescribed to elderly patients with peptic ulcer disease. Br J Clin Pharmacol 2002, 53(2): 183-188.

32. Honig PK, Gillespie BK: Clinical significance of pharmacokinetic drug interactions with over-the-counter (OTC) drugs. Clin Pharmacokinet 1998, 35(3):167-17|.

\section{Pre-publication history}

The pre-publication history for this paper can be accessed here:

http://www.biomedcentral.com/1472-6882/9/42/prepub
Publish with Bio Med Central and every scientist can read your work free of charge

"BioMed Central will be the most significant development for disseminating the results of biomedical research in our lifetime. "

Sir Paul Nurse, Cancer Research UK

Your research papers will be:

- available free of charge to the entire biomedical community

- peer reviewed and published immediately upon acceptance

- cited in PubMed and archived on PubMed Central

- yours - you keep the copyright
BioMedcentral 